\title{
Retention of radicular posts varying the application technique of the adhesive system and luting agent
}

\section{Retenção de pinos radiculares variando-se a técnica de aplicação do sistema adesivo e do agente cimentante}

\author{
Tabajara Sabbag Fonseca* \\ Edson Alfredo* \\ Luiz Pascoal Vansan* \\ Ricardo Gariba Silva* \\ Yara T. Correa Silva Sousa* \\ Paulo César Saquy* \\ Manoel D. Sousa-Neto*
}

\begin{abstract}
This study evaluated in vitro the retention of intracanal cast posts cemented with dual-cure resin varying the application method of the primer/adhesive solution and luting agent in the prosthetic space prepared to receive the posts. Sixty endodontically treated maxillary canines had their crowns discarded, and their roots were embedded in acrylic resin. The prosthetic spaces were prepared with Largo burs mounted on a low-speed handpiece coupled to a parallelometer in order to maintain length and diameter of intraradicular posts constant and to guarantee that the preparations were parallel after casting. Two groups $(n=30)$ were randomly formed according to the device used to apply the adhesive system: microbrush or standard bristle brush (control). Each group was divided into 3 subgroups $(n=10)$ according to the technique used to place the luting agent into the root canal: using only a lentulo spiral before setting the post, applying it onto the post surface, or combining both methods. After 72 hours, the tensile force required to dislodge each post was determined by a universal testing machine (Instron 4444) set at a speed of $1 \mathrm{~mm} /$ $\mathrm{min}$. The results indicated that the use of the microbrush yielded higher bond strength values $(0.1740 \pm 0.04 \mathrm{kN})$ than those recorded for the bristle brush tip $(0.1369 \pm 0.04 \mathrm{kN}, \mathrm{p}<0.001)$. Bonferroni's test demonstrated a higher retention $(\mathrm{p}<0.001)$ in radicular post cemented with the technique that combined both methods (lentulo + post: $0.1787 \pm 0.03 \mathrm{kN})$ than that obtained with lentulo $(0.1461 \pm 0.065 \mathrm{kN})$ or post $(0.1416 \pm 0.03 \mathrm{kN})$ alone. The interactions between the adhesive system and luting agent application techniques presented statistical difference $(p<0.001)$. It was concluded that the best performance in terms of tensile strength among the tested conditions was obtained when the adhesive system was applied with a microbrush and the luting agent was taken into the root canal with lentulo spirals alone $(0.1961 \pm 0.04 \mathrm{kN})$ and combining both methods (lentulo + post: $0.1911 \pm 0.02 \mathrm{kN}$ ) .
\end{abstract}

DESCRIPTORS: Adhesives; Tensile strength; Post and core technique; Dental cements.

RESUMO: O objetivo deste trabalho foi avaliar in vitro a retenção de pinos intra-radiculares variando-se a técnica de aplicação do agente adesivo e do cimento resinoso dual no espaço protético preparado para a recepção do pino. Sessenta caninos superiores tratados endodonticamente tiveram as coroas descartadas e as raízes incluídas em resina acrílica. Os espaços protéticos foram preparados com broca de Largo acionada por micromotor acoplado a um paralelômetro, a fim de manter constantes o comprimento e diâmetro dos pinos intra-radiculares e o paralelismo dos preparos após a fundição. Os pinos foram divididos aleatoriamente em 2 grupos $(\mathrm{n}=30)$ conforme a técnica de aplicação do agente adesivo: com "microbrush" ou com pincel (controle). Cada grupo foi subdividido em três subgrupos $(n=10)$ segundo a técnica de aplicação do agente cimentante: com o próprio pino, com broca de lentulo previamente ao posicionamento do pino ou associação dos dois modos. Após 72 horas do processo de cimentação, os pinos foram tracionados pela Máquina Universal de Ensaios (Instron 4444) à velocidade de $1 \mathrm{~mm} / \mathrm{min}$. Os resultados mostraram diferença estatística significante $(\mathrm{p}<0,001)$ entre as técnicas de aplicação do agente adesivo com "microbrush" $(0,1740 \pm 0,04 \mathrm{kN})$ e pincel $(0,1369 \pm 0,04 \mathrm{kN})$. Em relação à técnica de aplicação do cimento no interior do espaço protético, a da associação entre lentulo e pino $(0,1787 \pm 0,03 \mathrm{kN})$ foi estatisticamente diferente ( $\mathrm{p}<0,001)$ das do lentulo $(0,1461 \pm 0,065 \mathrm{kN})$ e do pino $(0,1416 \pm 0,03 \mathrm{kN})$ isoladamente. As interações entre as técnicas de aplicação do agente adesivo e do agente cimentante apresentaram diferença estatística $(p<0,001)$. Concluiu-se que as interações entre as técnicas de aplicação do agente adesivo com "microbrush" e aplicação do agente cimentante com lentulo $(0,1961 \pm 0,04 \mathrm{kN})$ e com lentulo e pino associados $(0,1911 \pm 0,02 \mathrm{kN})$ propiciaram os maiores valores da força de tração.

DESCRITORES: Adesivos; Resistência à tração; Técnica para retenção intra-radicular; Cimentos dentários.

\footnotetext{
* Department of Dentistry, School of Dentistry of Ribeirão Preto, University of Ribeirão Preto.
} 
Fonseca TS, Alfredo E, Vansan LP, Silva RG, Sousa YTCS, Saquy PC, Sousa-Neto MD. Retention of radicular posts varying the application technique of the adhesive system and luting agent. Braz Oral Res 2006;20(4):347-52.

\section{INTRODUCTION}

Radicular posts are a valuable resource in the prosthetic rehabilitation of teeth with extensive coronal destruction that still have adequate periodontal support and root implantation. ${ }^{1,5,12,18,22}$ However, the decision to use a post when restoring a root-filled tooth should primarily be based on the retention requirements of coronal restoration and is partly determined by the post design and bonding/luting procedures. . $^{2,10,13,18,22}$

In view of these shortcomings, attention was directed to improving luting material characteristics as well as the post fixation into the root canal space. ${ }^{2,9,12,20,21,25}$ The zinc phosphate cement has been traditionally used as a luting agent of radicular posts due to its low cost, ease of handling and fast setting. ${ }^{911,12,22}$ Nevertheless, the development of resin cements has currently been indicated for the cementation of metallic prosthetic pieces because its retention relies upon a strong mechanical interlocking with the dental surface..$^{2,4,6,15,29}$ Posts cemented with resin luting agents demand higher forces to be dislodged, ${ }^{4,16,19}$ they decrease coronal microleakage $\mathrm{e}^{3,6,13}$ and reinforce weakened root structure. ${ }^{15,21,23}$ Self-cure or dual-cure cements should be used due to the limited light penetration into the root, even with translucent posts. ${ }^{22}$

Concerning the techniques available for radicular post cementation, several studies have attempted to explain the divergent results found in literature regarding the bond strength they provided. ${ }^{2,5,9,12,14,21,24,25}$ Recently, Carvalho et al. ${ }^{4}$ (2004) and Alfredo et al. ${ }^{2}$ (2005) reported that the success in retention of cores and intracanal posts cemented with adhesive agents depend on a conjunction of factors including root canal preparation and operative procedures, specially the application method of the adhesive system and luting agent.

Disposable brush tips that are supplied with the adhesive systems were shown to be unable to carry the primer/adhesive solution to the apical region of the post-space preparation because of the progressive constriction of the root canals allied to the inadequate shape and length of brush bristles. ${ }^{7,8}$ Besides, it has been reported that when the luting agent is placed into the intracanal space and the posts are also coated with cement prior to insertion, post retention is increased. ${ }^{6,27}$

Despite the promising results of dual-cure resin luting agents, existing literature regarding the technique to promote optimal performance of the material is scarce and controversial. Therefore, the purpose of this study was to assess, by tensile bond strength testing, the retention of cast posts cemented with a dual-cure resin (Panavia F), varying the application method of the adhesive system (microbrush or standard bristle brush tip) and the placement technique of the luting agent into the root space (using only a lentulo spiral, applying it exclusively on the post surface or combining both methods).

\section{MATERIAL AND METHOD}

Sixty caries-free maxillary human canines, extracted within a six-month period for endodontic or periodontal reasons and stored in $0.9 \%$ saline solution, were cleaned with a scaler and water/pumice slurry in dental prophylactic cups. Each tooth was examined under a $10 \mathrm{X}$ stereomicroscope (Nikon Inc. Instrument Group, Melville, NY, USA) to discard those with structural defects. All the selected teeth had to have a single canal and a straight root measuring approximately $15 \mathrm{~mm}$.

Crowns were sectioned transversally $1 \mathrm{~mm}$ below the cemento-enamel junction with diamond discs (KG Sorensen, Barueri, SP, Brazil), under water cooling, and discarded. Roots were individually embedded in acrylic resin (Jet, Clássico, São Paulo, SP, Brazil) using a rectangular aluminum mold. Following the material polymerization, root canals were instrumented to a working length of $12 \mathrm{~mm}$ ( $1 \mathrm{~mm}$ above the anatomical apex) with $\mathrm{K}$ files (Dentsply-Maillefer, Ballaigues, Switzerland) up to a \#50 master apical file. During the instrumentation, canals were irrigated with $1 \%$ sodium hypochlorite. Final irrigation was done with $10 \mathrm{ml}$ of distilled water. The canals were aspirated and dried with absorbent paper points (Dentsply-Herpo, Petrópolis, RJ, Brazil). Root canals were obturated with gutta-percha points (Dentsply-Herpo, Petrópolis, RJ, Brazil) and Sealer 26 (Dentsply Ind. e Com. Ltda., Rio de Janeiro, RJ, Brazil) using the lateral condensation technique.

Root canal entrances were swabbed with alcohol and sealed with a non-eugenol temporary material (Vigodent, Rio de Janeiro, RJ, Brazil). The specimens were stored in distilled water at $37^{\circ} \mathrm{C}$ for 144 hours, corresponding to three times the endodontic sealer setting time. Samples were subsequently prepared with \#6 Largo burs (8-mm high; 1.7-mm diameter) (Dentsply-Maillefer, Ballaigues, Switzerland). A digital pachymeter (Digimess; Shiko Precision Gaging Ltd., China) was used to standardize the bur length and diameter. Cylindrical post spaces were prepared with a low- 
Fonseca TS, Alfredo E, Vansan LP, Silva RG, Sousa YTCS, Saquy PC, Sousa-Neto MD. Retention of radicular posts varying the application technique of the adhesive system and luting agent. Braz Oral Res 2006;20(4):347-52.

speed handpiece (Dabi Atlante, Ribeirão Preto, SP, Brazil) attached to a parallelometer (ELQuip, São Carlos, SP, Brazil) to ensure that the surface was kept parallel to the horizontal plane and obtain standard preparations with dentin walls parallel to the roots' long axis. Burs were replaced every ten preparations.

The prosthetic preparations were irrigated with distilled water, dried with absorbent paper points and isolated with silicon vaseline. For root canal impressions, a chemically activated acrylic resin (Duralay; Reliance Dental, Worth, IL, USA) and pin-jet posts (Ângelus-Odontológika, Londrina, PR, Brazil) were used. A 5-mm-long cylindrical core was fabricated with the same diameter as that of the intracanal portion. A special metallic ring was fixed to the core to allow bond testing in a universal machine.

The resin/wax pattern was embedded in a silicon ring with Termocast phosphate investment (Polidental, São Paulo, SP, Brazil) and cast in copperaluminum alloy (Goldent L.A. Com. Imp. Exp., São Paulo, SP, Brazil). The posts received an aluminum oxide blast and were adjusted to the root canals. The specimens had an 8-mm intracanal portion (post), a 5-mm coronal portion (core) and an 8-mm-diameter ring attached to the core (Figure 1).

The posts were cemented with Panavia F dualcure resin (Kuraray Co. Ltd., Osaka, Japan). The root canals were irrigated with distilled water and

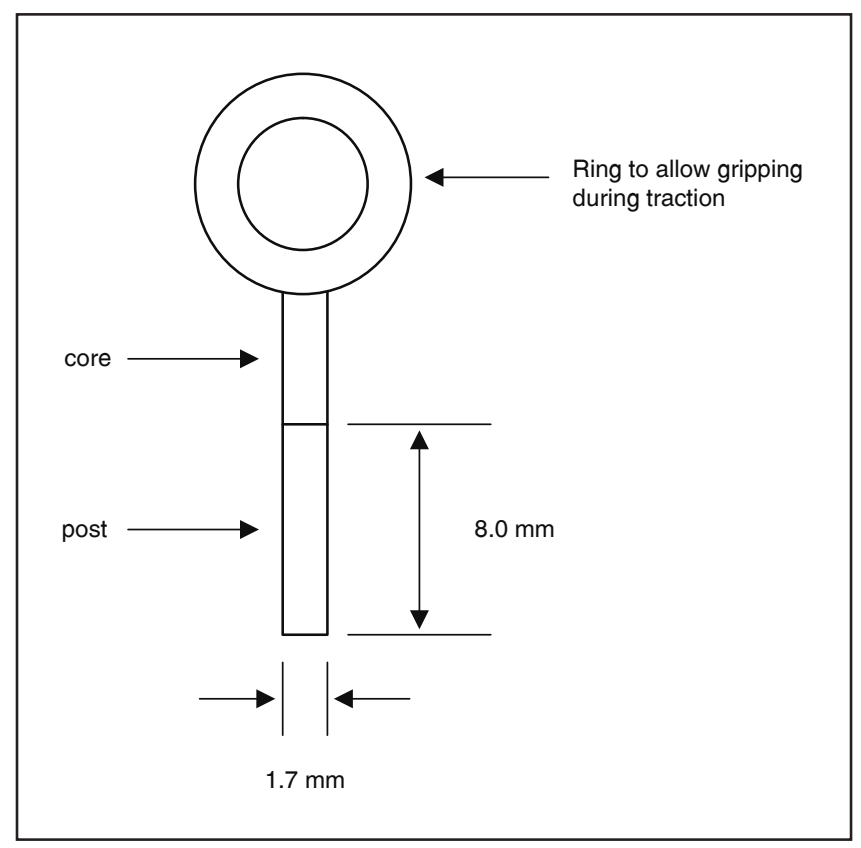

FIGURE 1 - Schematic drawing of the post-core configuration. dried with absorbent paper points. Sequentially, specimens were randomly assigned to two groups of equal size $(n=30)$ according to the application method of the adhesive system to the intracanal dentin: (A) using a microbrush applicator (Dentsply Ind. e Com. Ltda., Rio de Janeiro, RJ, Brazil) and (B) using a standard bristle brush tip supplied by the manufacturer (control). In all specimens, drops of each primer (Liquid A and Liquid B) were mixed for 5 seconds, and the mixture was applied to the dentin, left undisturbed for 60 seconds, and gently air-thinned to evaporate the volatiles.

Both groups were randomly divided into three subgroups $(n=10)$ according to the technique of placement of the luting agent into the post spaces: (I) using only a \#40 lentulo spiral (DentsplyMaillefer, Ballaigues, Switzerland), (II) applying exclusively on the post surface, or (III) combining both methods. The proper ratio of the catalyst and universal pastes were dispensed, mixed for $30 \mathrm{sec}-$ onds to create a uniform paste and the cement was taken into the root canal following the different proposed conditions.

The post-core settings were seated into the corresponding post space preparations, kept under digital pressure for 1 minute and the cement excess was removed. Light-activation (Ultralux Eletronic; Dabi Atlante, Ribeirão Preto, SP, Brazil) of the resin cement was done for 30 seconds at each surface (buccal, palatal, mesial and distal), resulting in a 2-minute light-curing cycle. Oxyguard II gel (Kuraray Co. Ltd., Osaka, Japan) was applied to the superficial margin for 10 minutes and then removed with cotton rolls and water spray.

After 72-hours storage in distilled water at $37^{\circ} \mathrm{C}$, the specimens were individually attached to a custom device apparatus, to be held secure in a vertical position and minimize the incidence of non-axial forces, in such a way that traction forces could be applied only parallel to the roots' long axis. This was necessary to avoid post pressure against the luting agent or dentin walls.

For each sample, the ring fixed to the core was grasped by a clamping apparatus in the universal testing machine (Instron 4444; Instron Corporation, Canton-Massachusetts, USA) and tensile force was applied at a crosshead speed of $1.0 \mathrm{~mm} /$ min until post dislodgement. The maximum force required for each post removal was recorded $(\mathrm{kN})$. Posts removed from the root canal space were observed with a $40 \mathrm{X}$ stereomicroscope (Nikon Inc. Instrument Group, Melville, NY 11747, USA) to assess the failure modes. 
Fonseca TS, Alfredo E, Vansan LP, Silva RG, Sousa YTCS, Saquy PC, Sousa-Neto MD. Retention of radicular posts varying the application technique of the adhesive system and luting agent. Braz Oral Res 2006;20(4):347-52.

Averages and standard deviations were calculated and the data were analyzed by two-way ANOVA using a factorial design with adhesive technique, and luting agent method as independent variables. Multiple comparisons were done using Bonferroni's test.

\section{RESULTS}

The tensile bond strength means and standard deviations required to dislodge the posts from the roots in the different experimental groups are presented in Table 1.

In general, statistical analysis of the data by ANOVA and by the Bonferroni test indicated significant differences $(\mathrm{p}<0.001)$ between the bond strength averages for the variables investigated (the technique of primer/adhesive application to the intracanal dentin and the method employed to take the luting agent into the root canal space).

The use of a microbrush applicator yielded higher tensile bond strength values than those recorded for the standard bristle brush tip $(\mathrm{p}<0.001)$. This means that the posts in the microbrush group offered superior resistance to being dislodged from the roots when submitted to traction forces.

The Bonferroni's test revealed statistically significant differences $(p<0.001)$ among the techniques of application of the luting agent into the root canals. Means comparisons yielded that the combination of both methods, in which the luting agent was taken into the root canal with a lentulo spiral and also spread onto the post surface (group III), promoted higher retention than the other tested techniques $(\mathrm{p}<0.001)$.

TABLE 1 - Bond strength means and standard deviations $(\mathrm{kN})$ required for post dislodgment, using different application methods of primer/adhesive solution and luting agent.

\begin{tabular}{|c|c|c|c|c|}
\hline \multirow{2}{*}{ Adhesive system application } & \multicolumn{4}{|c|}{ Luting agent placement } \\
\hline & Lentulo & Post & Lentulo + Post & Means $\pm \mathrm{SD}$ \\
\hline \multirow{10}{*}{ Microbrush } & 0.2495 & 0.1271 & 0.1801 & \multirow{10}{*}{$0.1740 \pm 0.04^{A}$} \\
\hline & 0.2245 & 0.1497 & 0.2055 & \\
\hline & 0.1245 & 0.1564 & 0.2130 & \\
\hline & 0.1306 & 0.1823 & 0.1905 & \\
\hline & 0.2410 & 0.1645 & 0.1875 & \\
\hline & 0.1817 & 0.1358 & 0.1955 & \\
\hline & 0.2154 & 0.0875 & 0.1564 & \\
\hline & 0.1650 & 0.1151 & 0.2250 & \\
\hline & 0.2340 & 0.0958 & 0.1745 & \\
\hline & 0.1945 & 0.1340 & 0.1835 & \\
\hline Means $\pm \mathrm{SD}$ & $0.1961 \pm 0.04$ & $0.1348 \pm 0.03$ & $0.1911 \pm 0.02$ & $0.1740 \pm 0.04$ \\
\hline \multirow{10}{*}{ Standard bristle brush tip } & 0.0979 & 0.1106 & 0.1825 & \multirow{10}{*}{$0.1369 \pm 0.04^{\mathrm{B}}$} \\
\hline & 0.0714 & 0.1760 & 0.1610 & \\
\hline & 0.1628 & 0.1339 & 0.2254 & \\
\hline & 0.0601 & 0.1152 & 0.1543 & \\
\hline & 0.1518 & 0.1959 & 0.1268 & \\
\hline & 0.0951 & 0.1401 & 0.1661 & \\
\hline & 0.1159 & 0.1549 & 0.1790 & \\
\hline & 0.0725 & 0.1669 & 0.1551 & \\
\hline & 0.0654 & 0.1251 & 0.1671 & \\
\hline & 0.0689 & 0.1654 & 0.1459 & \\
\hline Means $\pm \mathrm{SD}$ & $0.0962 \pm 0.03$ & $0.1484 \pm 0.03$ & $0.1663 \pm 0.02$ & \\
\hline Means \pm SD (Total) & $0.1461 \pm 0.06^{b}$ & $0.1416 \pm 0.03^{b}$ & $0.1787 \pm 0.03^{a}$ & \\
\hline
\end{tabular}

Upper case letters point to ANOVA's results $(\mathrm{p}<0.001)$. Lower case letters summarize Bonferroni's test results $(\mathrm{p}<0.001)$. Same letters indicate statistical similarity. 
Fonseca TS, Alfredo E, Vansan LP, Silva RG, Sousa YTCS, Saquy PC, Sousa-Neto MD. Retention of radicular posts varying the application technique of the adhesive system and luting agent. Braz Oral Res 2006;20(4):347-52.

The least resistance to post dislodgment was obtained when the primer/adhesive solution was applied to the intracanal dentin walls with a standard bristle brush tip and the resin cement was placed using only lentulo spirals.

After the tensile test, posts removed from the canal space showed cement adhering to the posts, indicating that adhesive failure occurred predominately in all groups.

\section{DISCUSSION}

The outcome of this study showed that the tensile force required to dislodge posts cemented with Panavia $F$ was superior when a microbrush was used as carrier of the primer/adhesive solution. These findings are consistent with those of previous studies ${ }^{7,8,29}$ that morphologically evaluated the shape and structure of different types of disposable applicators of adhesive systems into the root canal.

The greater post retention observed in the microbrush group may be ascribed to the fact that its long and malleable holder and the little tiny brush on its end allowed the application of a thin adhesive layer to intracanal dentin, including the apical third. ${ }^{8}$ Besides, it has been reported that a microbrush bends easily to any angle permitting the application of a homogeneous and controlled amount of primer/adhesive agent into limited access areas, promoting a more uniform resin-dentin interdiffusion zone and resin tags formation along the entire canal length, unlike that promoted with a standard brush. ${ }^{7,8}$

The importance of avoiding adhesive accumulation in the apical third is even better understood when taking into account that the restricted access to this area creates additional difficulty for the luting agent light-activation process, which makes this region predisposed to post displacement until complete cement setting. ${ }^{13,22,26}$

It has been speculated that primer/adhesive application with standard brush tips that are supplied together with the adhesive systems probably results in solution accumulation into the postspace apical region that limits solvents volatilization and may interfere in the polymerization procedure. ${ }^{4,29}$ Moreover, the inappropriate shape and dimensions of disposable bristle brush tips were unable to homogeneously apply the adhesive solution into constricted root apical areas. ${ }^{8}$

The post analysis after its removal from the canal space showed a predominance of the adhesive- failure mode in all groups. Pithan et al. ${ }^{17}$ (2002) also described the prevalence of adhesive failure in intracanal posts. These findings indicate that failure after testing mostly occurred at the interface between the luting agent and radicular dentin, and suggests that the bond strength values recorded were, in fact, representative and provided a reliable estimate of the adhesive resistance yielded by the tested conditions.

According to the manufacturer's instructions, the Panavia F system should be taken into the root canal by applying a thin layer of cement over the post before setting it in position. However, the results of the conducted study revealed that the highest resistance to post dislodgment was obtained when the luting agent was taken into the root space with a lentulo spiral and also spread onto the post surface. An earlier investigation $^{2}$ found bubble formation and incomplete luting when Panavia F cement was not previously placed into the root canal space but only applied to the post. This would be an unavoidable result and could interfere with the effective interaction between cement and intracanal dentin walls.

The use of lentulo spirals permits a favorable distribution of luting cement throughout the post space and formation of a uniform, continuous cement layer. ${ }^{4,9}$ In this situation, if a dual-cure resin was the selected cementing material, the major recommendation is to avoid partial polymerization before the adequate post seating and excess material removal. ${ }^{16,18,22,28}$

Regarding the different combinations of techniques for primer/adhesive application and luting agent placement, the lowest tensile bond strengths were found when the adhesive agent was applied with a bristle brush tip and the resin cement was taken into the root canal using solely a lentulo spiral. A possible explanation for such result would be that bristle brush tips usually take a greater amount of adhesive agent into the root canal. ${ }^{4}$ The excess of solution mixes with the resin cement when the lentulo spiral is operating in the canal. ${ }^{4,7}$ This mixture could interfere in the luting agent's original composition and affect negatively its physicochemical properties. ${ }^{2,4,28}$ Therefore, the routine combination of these techniques in clinical practice should be avoided.

The lack of published data investigating the application method of adhesive solution and luting agent to the root canal, particularly with dual-cure resin cements, hinders the settlement of reliable comparisons. In addition, the great variety of current dental materials is a crucial feature to be con- 
Fonseca TS, Alfredo E, Vansan LP, Silva RG, Sousa YTCS, Saquy PC, Sousa-Neto MD. Retention of radicular posts varying the application technique of the adhesive system and luting agent. Braz Oral Res 2006;20(4):347-52.

sidered. Further research is necessary to disclose which material and luting protocol is appropriate for each individual clinical situation.

\section{CONCLUSION}

Based on these findings, and within the limitations of an in vitro study, it may be concluded that:

\section{REFERENCES}

1. Abou-Rass M. Post and core restoration of endodontically treated teeth. Curr Opin Dent. 1992;2(3):99-107.

2. Alfredo E, Carvalho-Junior JR, Silva-Sousa YT, Correr-Sobrinho L, Saquy PC, Sousa-Neto MD. Evaluation of retention of post-core system cemented with different materials on dentine surfaces treated with EDTA or Er:YAG laser irradiation. Photomed Laser Surg. 2005;23(1):36-40.

3. Bachicha WS, DiFiore PM, Miller DA, Lautenschlager EP, Pashley DH. Microleakage of endodontically treated teeth restored with posts. J Endod. 1998;24(11):703-8.

4. Carvalho RM, Carrilho MRO, Pereira LCG, Garcia FCP, Marquesini-Junior L, Silva SMA. Adhesive systems: background information for understanding their clinical application and performance. Biodont. 2004;2(1):61-4.

5. Cohen BI, Pagnillo MK, Newman I, Musikant BL, Deutsch AS. Retention of three endodontic posts cemented with five dental cements. J Prosthet Dent. 1998;79(5):520-5.

6. El-Mowafy OM, Milenkovic M. Retention of paraposts with dentin-bonded resin cements. Oper Dent. 1994;19(5):17682.

7. Ferrari M, Grandini S, Simonetti M, Monticelli F, Goracci C. Influence of a microbrush on bonding fiber post into root canals under clinical conditions. Oral Surg Oral Med Oral Pathol Oral Radiol Endod. 2002;94(5):627-31.

8. Ferrari M, Vichi A, Grandini S, Geppi S. Influence of microbrush on efficacy of bonding into root canals. Am J Dent. 2002;15(4):227-31.

9. Garrido AD, Fonseca TS, Alfredo E, Silva-Sousa YT, SousaNeto MD. Influence of ultrasound, with and without water spray cooling, on removal of posts cemented with resin or zinc phosphate cements. J Endod. 2004;30(3):173-6.

10. Goldman M, DeVitre R, Pier M. Effect of the dentin smear layer on tensile strength of cemented posts. J Prosthet Dent. 1984;52(4):485-8.

11. Johnson JK, Sakumura JS. Dowel form and tensile force. J Prosthet Dent. 1978;40(6):645-9.

12. Leary JM, Holmes DC, Johnson WT. Post and core retention with different cements. Gen Dent. 1995;43(5):4169.

13. Love RM, Purton DG. Retention of posts with resin, glass ionomer and hybrid cements. J Dent. 1998;26(7):599602.

14. McSherry PF. An in vitro evaluation of the tensile and shear strengths of four adhesives used in orthodontics. Eur J Orthod. 1996;18(4):319-27.

15. Mendoza DB, Eakle WS, Kahl EA, Ho R. Root reinforcement with a resin-bonded preformed post. J Prosthet Dent. 1997;78(1):10-4.
In radicular cast posts luted with dual-cure resin cement (Panavia F), the best performance among the tested conditions was obtained when the adhesive system was applied with a microbrush applicator and the luting agent was taken into the root canal with lentulo spirals and also spread onto the post surface.

16. Mitchell CA. Selection of materials for post cementation. Dent Update. 2000;27(7):350-4.

17. Pithan S, Vieira RS, Chain MC. Tensile bond strength of intracanal post in primary anterior teeth: an in vitro study. J Clin Pediatr Dent. 2002;27(1):35-9.

18. Ricketts DN, Tait CM, Higgins AJ. Tooth preparation for post-retained restorations. Br Dent J. 2005;23(8):46371.

19. Sahmali S, Demirel F, Saygili G. Comparison of in vitro tensile bond strengths of luting cements to metallic and tooth-colored posts. Int J Periodontics Restorative Dent. 2004;24(3):256-63.

20. Satterthwaite JD, Stokes AN. Effect of ultrasonic vibration on the retention of adhesively luted intra-radicular posts. Eur J Prosthodont Restor Dent. 2004;12(3):101-4.

21. Saupe WA, Gluskin AH, Radke RA Jr. A comparative study of fracture resistance between morphologic dowel and cores and resin-reinforced dowel system in the intraradicular restoration of structurally compromised roots. Quintessence Int. 1996;27(7):488-91.

22. Schwartz RS, Robbins JW. Post placement and restoration of endodontically treated teeth: a literature review. J Endod. 2004;30(5):289-301.

23. Sen D, Poyrazoglu E, Tuncelli B. The retentive effects of pre-fabricated posts by luting cements. J Oral Rehabil. 2004;31(6):585-9.

24. Souza-Filho CB, Paulino SM, Alfredo E, de SousaNeto MD, Vansan LP. Effect of the diameter on $\mathrm{Cu}-\mathrm{Al}$ post retention. Braz Oral Res. 2004;18(3):238-41.

25. Standlee JP, Caputo AA, Hanson EC. Retention of endodontic dowels: Effects of cement, dowel length, diameter and design. J Prosthet Dent. 1978;39(4):401-5.

26. Stern N, Hirshfeld Z. Principles of preparing endodontically treated teeth for dowel and core restorations. J Prosthet Dent. 1973;30(2):62-5.

27. Turner $\mathrm{CH}$. The retention of dental posts. J Dent. 1982;10(2):154-65.

28. Utter JD, Wong BH, Miller BH. The effect of cementing procedures on retention of prefabricated metal posts. J Am Dent Assoc. 1997;128(8):1123-7.

29. Vichi A, Grandini S, Ferrari M. Comparison between two clinical procedures for bonding fiber posts into a root canal: A Microscopic Investigation. J Endod. 2002;28(5):35560.
Received for publicaton on Aug 01, 2006

Sent for alterations on Aug 30, 2006 Accepted for publication on Sep 20, 2006 